\title{
Without progress no funding
}

\section{ROBERT J. GELLER}

Wyss asserted that without funding at "a scale comparable to the funding of astrophysical research ... serious progress toward learning how to predict earthquakes" was impossible. However, extensive prediction efforts in several countries in several eras have all failed. Further allocation of public funds appears unwarranted unless there are specific and compelling grounds for thinking that a proposed new prediction programme will be successful.

In my first article in this debate I said that over the past 100 years, and particularly since 1960, there had been great efforts, all unsuccessful, to find precursory phenomena that could be used to make reliable and accurate predictions of earthquakes. Wyss claims that this statement is incorrect, but below I would like to demonstrate its veracity.

\section{A tale of two countries}

In 1891 the Nobi (sometimes called Mino-Owari) earthquake caused significant damage in Japan. In response, the Japanese government established the Imperial Earthquake Investigation Committee in 1892. Imamura (Ref. 1, p. 346), a well-known seismologist, wrote as follows in 1937: "[The Committee] attacked with every resource at their command the various problems bearing on earthquake prediction, such as earth tiltings and earth pulsations, variation in the elements of terrestrial magnetism, variation in underground temperatures, variation in latitude, secular variation in topography, etc., but satisfactory results were not obtained".

J.B. Macelwane ${ }^{2}$, also a leading seismologist of his day (one of the major medals of the American Geophysical Union is named in his honour), commented as follows in 1946. "The problem of earthquake forecasting has been under intensive investigation in California and elsewhere for some forty years, and we seem to be no nearer a solution of the problem than we were in the beginning. In fact the outlook is much less hopeful."

Thus the existence of prediction research efforts before 1960 is supported by two leading authorities of the era. One stated that a government body had attacked the prediction problem "with every resource at their command" without obtaining satisfactory results, and another that "intensive investigations" "in California and elsewhere for some forty years" had not led to any progress towards prediction.

\section{Only in America?}

Wyss says that "no prediction research program existed before the 1970s". Even if the efforts reported by Imamura and Macelwane were disregarded, Wyss's statement would still be incorrect unless applied only to work in the US.

Japan's prediction research program started in $1965^{3}$, and the Soviet prediction research program started in the Garm "polygon" (test field area for intensive geophysical observations) shortly after the 1948 Ashkhabad earthquake ${ }^{4}$. These substantial efforts by qualified professionals should not be ignored just because they were not in the US or western Europe.

Japan has spent about $2 \times 10^{11}$ Yen on earthquake prediction since 1965 (Asahi Shinbun newspaper, 10 January 1998), but this programme has been unsuccessful 5,6 . Before adopting Wyss's suggestion of funding prediction research "at a scale comparable to the funding of astrophysical research", US 
government authorities should find out what went wrong in Japan. The set of possible explanations lies between two extremes.

1. Owing to some unknown difference, the seismologists in Japan failed when their counterparts in the US, would have succeeded if only they had had comparable funding.

2. The goals and methods of the programme were completely unrealistic.

Needless to say, I think (2) is correct. Nature's Tokyo correspondent appears to share my views ${ }^{7}$. As Wyss is implicitly advocating position (1), he should explain his reasons for taking this view.

\section{The bottom line}

All of the debaters, including both Wyss and myself, agree that scientifically sound efforts to improve our knowledge of the earthquake source process should be made. We can be cautiously optimistic that, in the long run, such work may indirectly contribute to the mitigation of earthquake hazards. However, proposed work in this area should be evaluated by the normal peer-review process and should not be labelled as "earthquake prediction" research.

\section{Robert J. Geller}

Department of Earth and Planetary Physics,

Graduate School of Science,

Tokyo University,

Bunkyo,

Tokyo 113-0033,

Japan.

bob@global.geoph.s.u-tokyo.ac.jp

\section{References}

1. Imamura, A. Theoretical and Applied Seismology. (Maruzen, Tokyo, 1937).

2. Macelwane, J.B. Forecasting earthquakes. Bull. Seism. Soc. Am. 36, 1-4 (1946). (reprinted in Geophys. J. Int. 131, 421-422, 1997).

3. Kanamori, H. Recent developments in earthquake prediction research in Japan, Tectonophysics 9, 291-300 (1970).

4. Savarensky, E.F. On the prediction of earthquakes. Tectonophysics $\mathbf{6}$, 17-27 (1968).

5. Geller, R.J. Earthquake prediction: a critical review. Geophys. J. Int. 131, 425-450 (1997).

6. Saegusa, A., Japan to try to understand quakes, not predict them Nature, 397, 284 (1999).

7. Swinbanks, D. Without a way to measure their success, Japanese projects are very hard to stop. Nature, 357, 619 (1992). 